\title{
Solid-state structure and optical properties of highly fluorescent diketopyrrolopyrrole derivatives synthesized by cross-coupling reaction
}

Junpei Kuwabara, Takuya Yamagata, and Takaki Kanbara*

Tsukuba Research Center for Interdisciplinary Materials Science (TIMS),

Graduate School of Pure and Applied Sciences University of Tsukuba,

1-1-1 Tennodai, Tsukuba 305-8573, Japan

\section{Graphical abstract}

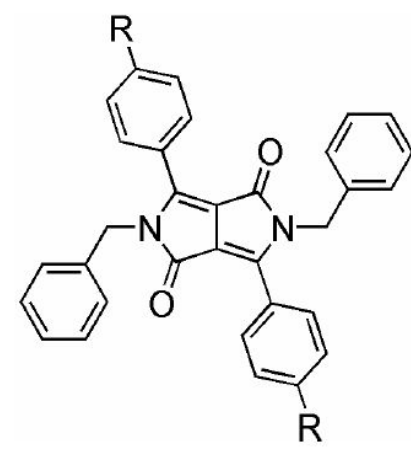

$1: \mathrm{R}=-\xi-\mathrm{Cl}$

$2: R=-\xi-O$

$3: \mathrm{R}=\left\{\mathrm{C}_{6} \mathrm{H}_{13}\right.$

$4: \mathrm{R}=-\xi-\square-\mathrm{OC}_{4} \mathrm{H}_{9}$
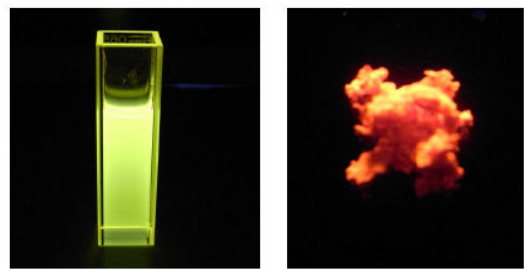
Manuscript submitted to Tetrahedron

\title{
Solid-state structure and optical properties of highly fluorescent diketopyrrolopyrrole derivatives synthesized by cross-coupling reaction
}

\author{
Junpei Kuwabara, Takuya Yamagata, and Takaki Kanbara* \\ Tsukuba Research Center for Interdisciplinary Materials Science (TIMS), \\ Graduate School of Pure and Applied Sciences University of Tsukuba, \\ 1-1-1 Tennodai, Tsukuba 305-8573, Japan
}

\begin{abstract}
Diketopyrrolopyrrole (DPP) derivatives with four different substituents were synthesized by cross-coupling reactions. The DPP derivatives were investigated in terms of their solid-state structure, absorption, emission and electrochemistry. The electron-donating property of each substituent causes a redshift of UV/Vis absorption and emission in the solution state. Although all of the DPP derivatives have high quantum yields in solution, only butoxyphenyl-substituted DPP exhibits strong emission in the solid state.
\end{abstract}

Keywords: Diketopyrrolopyrrole/ Fluorescence/ Cross-coupling reaction/ Solid-state structure

\section{Introduction}

Diketopyrrolopyrrole (DPP) and its derivatives were originally used to color plastics, surface coatings and color filters owing to their brilliant color and high stability. ${ }^{1}$ In recent years, DPP derivatives have been recognized as new functional dyes in the field of material sciences. For example, DPP derivatives for light-emitting diodes ${ }^{2}$ and dye lasers $^{3}$ have been developed by utilizing their efficient emission in the visible region.

* Corresponding author. Tel.: (+81)29-853-5137; fax: (+81)29-853-4490; E-mail: kanbara@ims.tsukuba.ac.jp (T. Kanbara). 
Since DPP-containing polymers have good potential for use as charge carriers, they have been applied in organic solar cells ${ }^{4}$ and organic thin-film transistors (OTFTs). ${ }^{5}$ Since the properties of DPP derivatives strongly depend on the electron density of the aromatic groups attached to the central DPP core, efficient methods of introducing a desired substituent onto the aromatic groups are greately required to enable the discovery of new materials. Until now, most DPP derivatives have been synthesized by the reaction of a succinate ester and benzonitrile derivatives via a cyclization. ${ }^{1}$ However, in the case of DPP with electron-donating groups, the synthetic method gives a low yield of the product. $^{2 b, 3}$ Meanwhile, a Cl-substituted DPP, Pigment Red 254, is commercially available and inexpensive. This prompted us to investigate the postfunctionalization of $\mathrm{DPP}^{6}$ at the aryl halide moieties by an organometallic catalysis ${ }^{7}$ instead of by the conventional method. In the previous communication, we reported the synthesis of an amine-functionalized DPP from Pigment Red 254 by a Pd-catalyzed amination reaction. ${ }^{8}$ Nowadays, a variety of cross-coupling reactions of aryl chlorides are available for constructing the desired structure. ${ }^{9}$ Therefore, one can expect to obtain new DPP derivatives by the introduction of substituents via cross-coupling reactions, which should make it possible to elucidate the effect of substituents on the optical properties. Herein, we report the syntheses of a series of DPP derivatives by organometallic cross-coupling reactions. The DPP derivatives were investigated in terms of their solid-state structure, absorption, emission and electrochemistry to gain information about the relationship between these properties and the substituent on the aromatic ring. Since the optical properties in the solid state are highly dependent on the intermolecular interaction, ${ }^{10}$ the solid-state emission of DPP derivatives is discussed in view of their aggregation behaviours. 


\section{Results and discussion}

\subsection{Syntheses of DPPs by cross-coupling reactions}

The Cl-substituted compound $\mathbf{1}$ and the morpholine-substituted compound $\mathbf{2}$ were synthesized in accordance with the previous report (Scheme 1). ${ }^{8}$ The introduction of benzyl groups into Pigment Red 254 resulted in good solubility in organic solvents and allowed the convenient functionalization of DPP by several organometallic cross-coupling reactions. The 1-octenyl and 4-butoxyphenyl groups were introduced by the Suzuki-Miyaura coupling reaction with 2-(2',6'-dimethoxybiphenyl)-dicyclohexylphosphine (SPhos) $)^{11}$ as a ligand, which produces the corresponding compounds 3 and $\mathbf{4}$ with 95 and 93\% yields, respectively. SPhos is crucial for the activation at the aryl-Cl moiety under the mild conditions that are necessary to prevent the decomposition of the DPP moiety. The ${ }^{1} \mathrm{H}$ NMR spectrum of $\mathbf{3}$ exhibits a set of olefinic resonances at 6.33 and $6.38 \mathrm{ppm}$ with a $15.8 \mathrm{~Hz}$ coupling constant, which indicates the trans configuration. Since the cis isomer was not observed in the crude product, the reaction occurred with the retention of the configuration of trans-1-octen-1-ylboronic acid. The configuration of compound $\mathbf{3}$ was also confirmed by the X-ray diffractional study (see below).

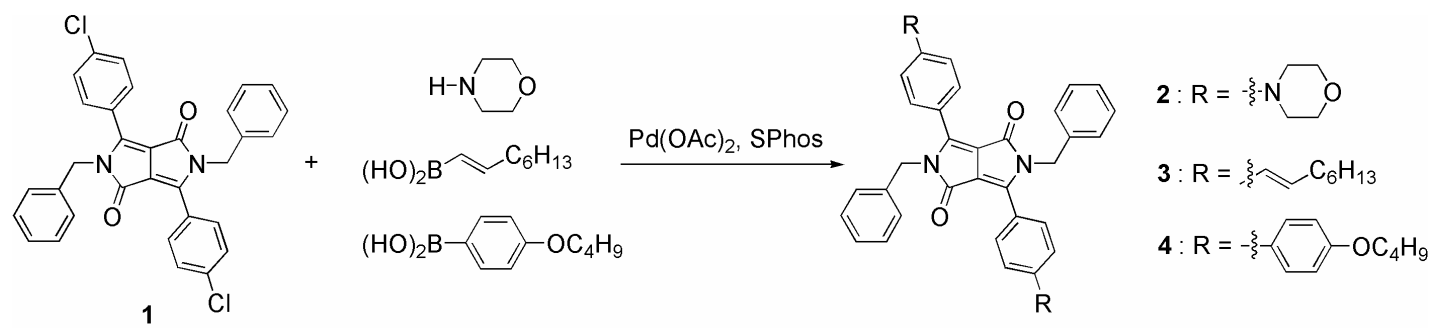

Scheme 1 


\subsection{Solid-state structure}

The solid-state molecular structures of $\mathbf{1}$ and $\mathbf{3}$ were obtained by the X-ray diffractional studies. Single crystals of $\mathbf{1}$ suitable for the X-ray diffraction study were obtained by the slow diffusion of hexane into its solution in $\mathrm{CHCl}_{3} .{ }^{12}$ The crystal structure of $\mathbf{1}$ is shown in Fig. 1a. Compound 1 crystallizes in the monoclinic space group $\mathrm{P} 2{ }_{1} / \mathrm{c}$ with an inversion center at the midpoint of $\mathrm{C} 2$ and $\mathrm{C} 2 *$. In the crystal lattice, intermolecular $\pi-\pi$ stacking of the phenyl ring is observed with a distance of $3.5 \AA$ (Fig. S-1 in supplementary data). Single crystals of $\mathbf{3}$ were also obtained by the slow diffusion of hexane into its solution in $\mathrm{CHCl}_{3}{ }^{13}$ Similarly to $\mathbf{1}$, compound $\mathbf{3}$ crystallizes in the space group $\mathrm{P} 2{ }_{1} / \mathrm{c}$ but without an inversion center in the crystal structure. An ORTEP drawing of $\mathbf{3}$ shows the trans configuration of the olefinic moiety (Fig. 1b). The packing diagram of the crystal indicates stacking of the olefinic moiety and a double bond in the lactam moiety (Fig. S-2). Table 1 exhibits the selected bond lengths and angles of $\mathbf{1}$ and $\mathbf{3}$ as well as those reported for compound 2 for comparison. ${ }^{8}$ In terms of bond length, the morpholine-substituted compound $\mathbf{2}$ has unique characteristics. Compound $\mathbf{2}$ has longer $\mathrm{C} 1-\mathrm{O} 1$ and $\mathrm{C} 2-\mathrm{C} 3$ bonds and shorter $\mathrm{C} 1-\mathrm{C} 2$ and $\mathrm{C} 3-\mathrm{C} 11$ bonds than those in compounds 1 and 3. This can be explained by the contribution of the resonance structure with the charge transfer shown in Scheme 2. In addition, the substituent affects the dihedral angle between the DPP core and the phenyl group bearing the substituents. The dihedral angle increases with decreasing electron-donating ability of the substituent; $2\left(28.1^{\circ}\right)<3\left(33.6^{\circ}\right)<\mathbf{1}\left(45.0^{\circ}\right)$. The electron-donating substituent increases the electron density on the phenyl ring, resulting in efficient conjugation between the DPP core and the phenyl ring. 
(a)

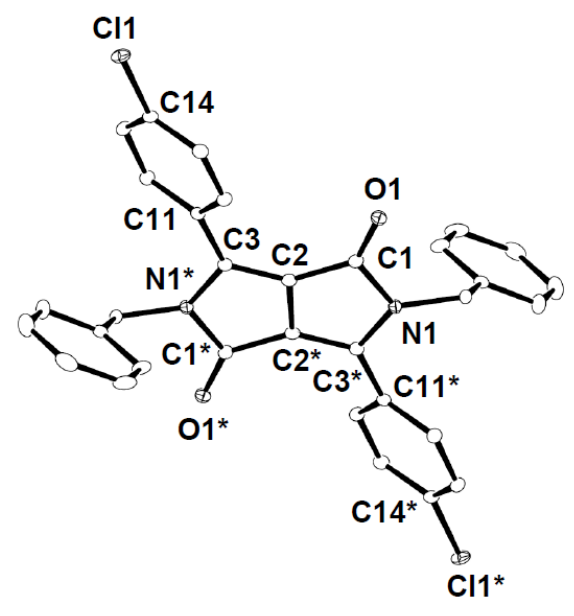

(b)

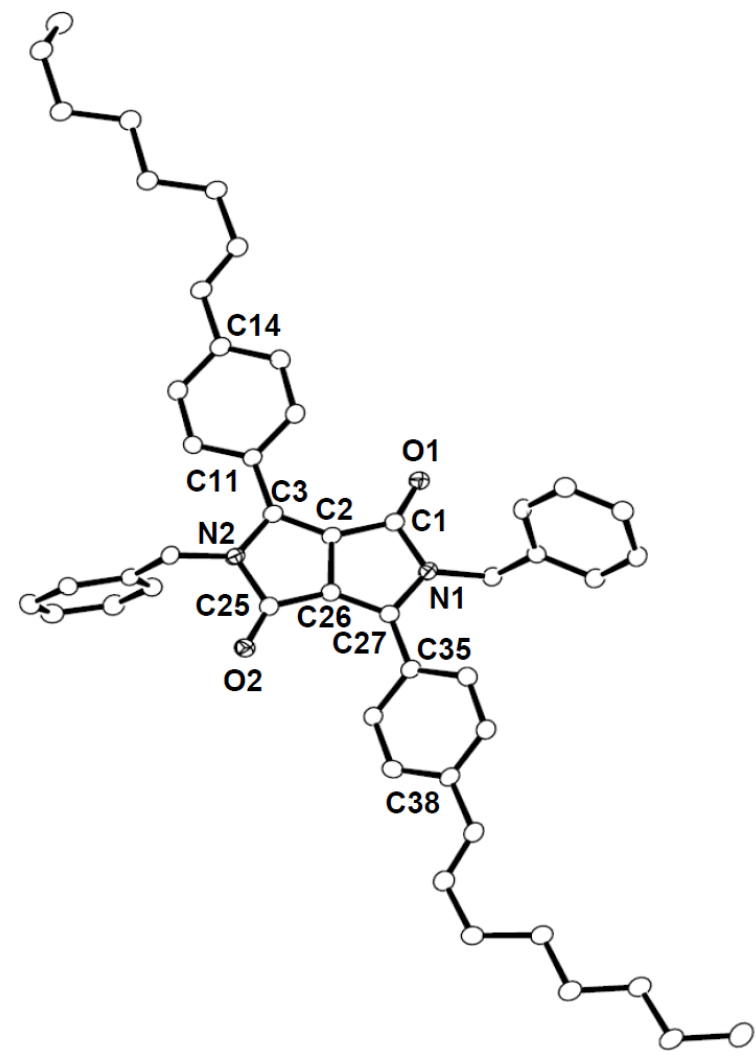

Fig. 1. (a) ORTEP drawing of 1 with thermal ellipsoids shown at the $30 \%$ probability level and (b) ORTEP drawing of $\mathbf{3}$ with thermal ellipsoids shown at the 30\% probability level. Hydrogen atoms are omitted for clarity. Atoms with asterisks are crystallographically equivalent to those having the same number without asterisks.

Table 1.

Selected Bond Lengths $(\AA)$ and Angles (deg) for Compound 1-3

\begin{tabular}{lccc}
\hline & $\mathbf{1}$ & $\mathbf{2}^{\mathrm{d}}$ & $\mathbf{3}$ \\
\hline $\mathrm{C} 1-\mathrm{O} 1$ & $1.223(2)$ & $1.238(4)$ & $1.220(4)$ \\
$\mathrm{C} 1-\mathrm{N} 1$ & $1.427(2)$ & $1.423(4)$ & $1.427(4)$ \\
$\mathrm{C} 1-\mathrm{C} 2$ & $1.456(2)$ & $1.437(4)$ & $1.454(4)$ \\
$\mathrm{C} 2-\mathrm{C} 3$ & $1.369(2)$ & $1.392(3)$ & $1.384(4)$ \\
$\mathrm{C} 2-\mathrm{C} 2 * \mathrm{a}$ & $1.426(2)$ & $1.418(4)$ & $1.427(4)$ \\
$\mathrm{C} 3-\mathrm{C} 11$ & $1.464(2)$ & $1.457(4)$ & $1.464(4)$ \\
$\mathrm{C} 2-\mathrm{C} 3-\mathrm{C} 11$ & $129.2(2)$ & $129.1(2)$ & $128.5(3)$ \\
$\mathrm{C} 11-\mathrm{C} 3-\mathrm{N} 1{ }^{\mathrm{b}}$ & $123.3(2)$ & $124.6(2)$ & $124.8(2)$ \\
Dihedral angle & 45.0 & 28.1 & 33.6 \\
\hline${ }^{\mathrm{a}} \mathrm{C} 2 *$ indicates $\mathrm{C} 26$ in compound $3 .{ }^{\mathrm{b}} \mathrm{N} 1 *$ indicates $\mathrm{N} 2$ in \\
compound 3. ${ }^{\mathrm{c}}$ The dihedral angle between the DPP core and the \\
phenyl group. ${ }^{\mathrm{d}}$ From reference 8.
\end{tabular}




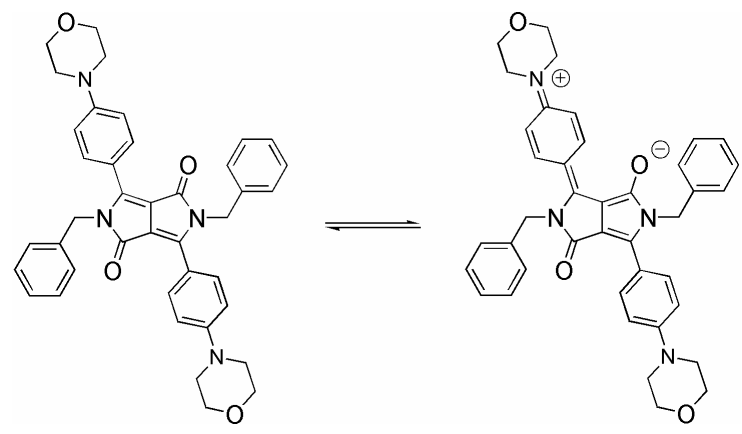

Scheme 2

In the case of compound 4 , a single crystal suitable for an X-ray diffraction study could not be obtained. In most cases, crystallization processes gave a thin fibrous solid in contrast to the blockish crystals of 1-3. Fig. 2 shows a scanning electron microscope (SEM) image of the fibrous solid. Most of the fibers are more than $200 \mu \mathrm{m}$ long with a cross-sectional width of a few micrometers. A powder X-ray diffraction study was performed on the fibrous solid. The sharp diffraction pattern of the fibrous solid indicates a crystalline form (Fig. S-3).

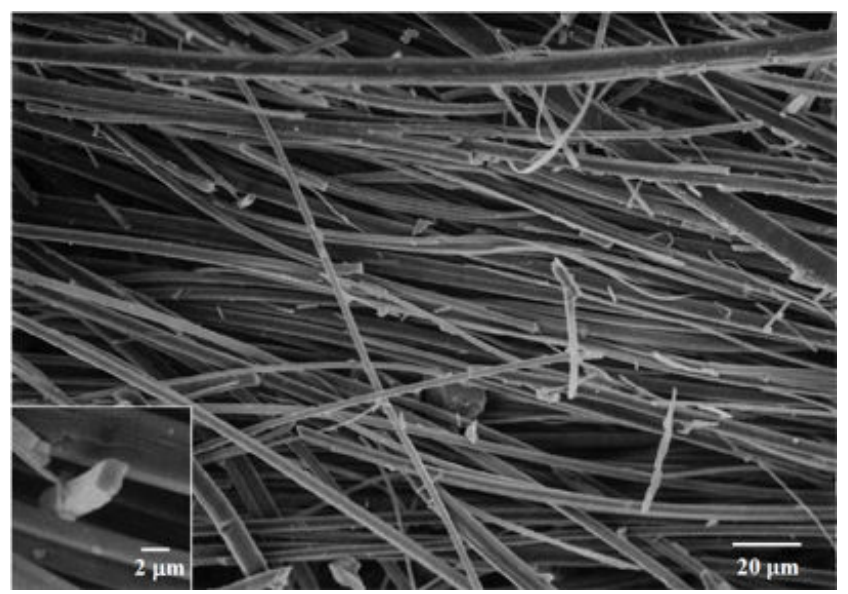

Fig. 2. SEM image of 4.

\subsection{Electrochemistry}


The cyclic voltammograms of 1-4 exhibit a reversible anodic redox couple (Fig. 3). Owing to the electron-withdrawing property of the $\mathrm{Cl}$ substituents, the reduction of $\mathbf{1}$ occurs at a more positive potential $\left(E_{1 / 2}=-1.62 \mathrm{~V} \mathrm{vs} \mathrm{Fc}^{+} / \mathrm{Fc}\right)$ than those of $2(-1.87 \mathrm{~V}), \mathbf{3}$ $(-1.72 \mathrm{~V})$ and $4(-1.69 \mathrm{~V})$. Since compound 2 has the most negative reduction potential owing to the electron-donating morpholine substituent, it is clear that the substituent affects the electronic state of the DPP core through the aromatic ring. In addition, only 2 exhibits an anodic redox couple at $0.27 \mathrm{~V}$, which is probably due to the two-electron oxidation of the morpholinyl moieties. ${ }^{8}$

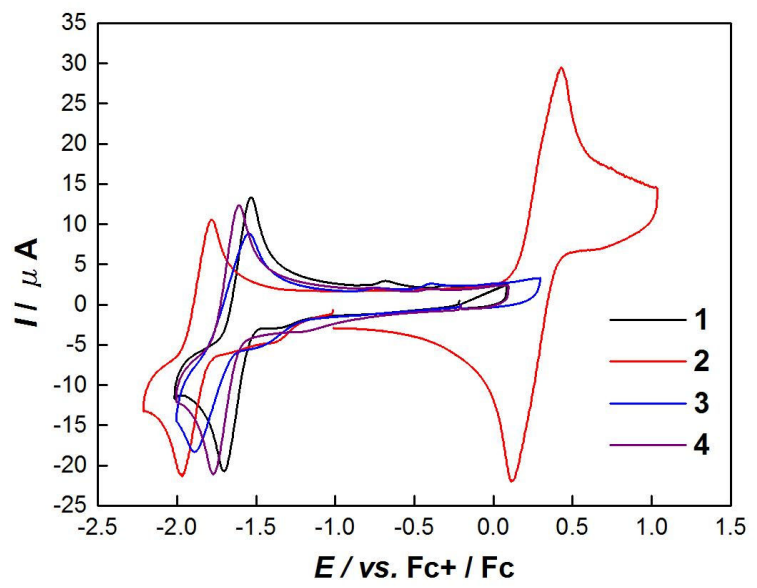

Fig. 3. Cyclic voltammograms of $\mathbf{1 - 4}$ in $\mathrm{CH}_{2} \mathrm{Cl}_{2}\left(1 \times 10^{-3} \mathrm{M}\right)$ containing $\mathrm{Bu}_{4} \mathrm{NPF}_{6}(0.1$ M). Sweep rate $=100 \mathrm{mVs}^{-1}$.

\subsection{UV/Vis absorption spectroscopy and DFT calculation}

The optical properties of compounds $\mathbf{1 - 4}$ are summarized in Table 2. The UV/Vis absorption spectra of compounds 1-4 were measured in $\mathrm{CHCl}_{3}$ (Fig. 4). The electron-donating ability of the substituent affords a redshift of the absorbance maxima $\left(\lambda_{\max }\right)$, the order of $\lambda_{\max }$ is $\mathbf{2}>\mathbf{4} \approx \mathbf{3}>\mathbf{1}$. This order also applies to the molar absorbance coefficient $(\varepsilon)$. Indeed, the morpholine-substituted compound $\mathbf{2}$ has almost double the value of $\varepsilon\left(4.23 \times 10^{4} \mathrm{Lmol}^{-1} \mathrm{~cm}^{-1}\right)$ than that of the Cl-substituted compound $1\left(2.18 \times 10^{4}\right.$ $\left.\mathrm{Lmol}^{-1} \mathrm{~cm}^{-1}\right)$. 


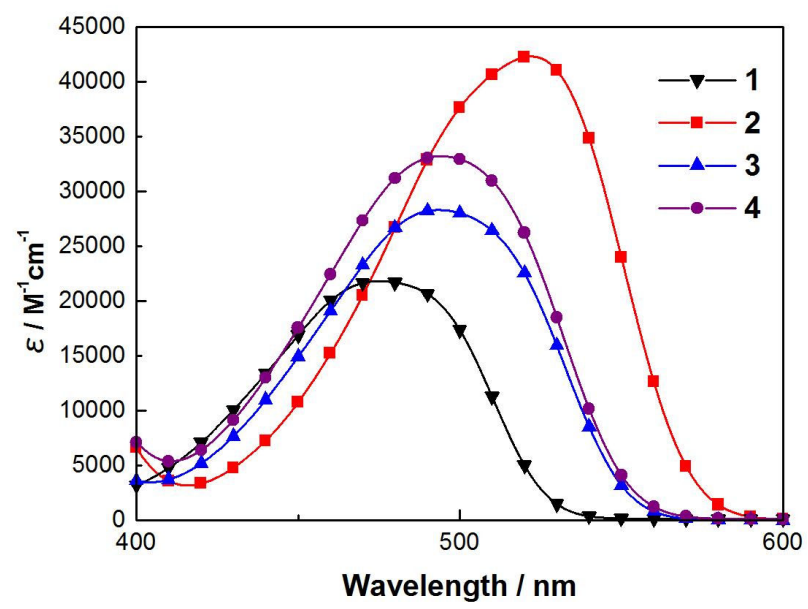

Fig. 4. UV/Vis absorption spectra of $\mathbf{1 - 4}$ in $\mathrm{CHCl}_{3}$.

Table 2.

Photophysical Properties of 1-4

\begin{tabular}{|c|c|c|c|c|c|c|c|}
\hline \multirow[t]{2}{*}{ Compound } & \multicolumn{2}{|c|}{$\mathrm{UV}^{\mathrm{a}}$} & \multicolumn{2}{|c|}{$\operatorname{PL}\left(\lambda_{\mathrm{em}} / \mathrm{nm}\right)^{\mathrm{c}}$} & \multirow{2}{*}{$\begin{array}{c}\text { Stokes shift }\left(\mathrm{cm}^{-1}\right) \\
\text { in solution }\end{array}$} & \multicolumn{2}{|c|}{$\Phi_{\mathrm{f}}^{\mathrm{c}}$} \\
\hline & $\left(\lambda_{\max } / \mathrm{nm}\right)$ & $\left(\varepsilon / \mathrm{Lmol}^{-1} \mathrm{~cm}^{-1}\right)$ & solution $^{\mathrm{a}}$ & solid $^{\mathrm{b}}$ & & solution $^{\mathrm{a}}$ & solid $^{\mathrm{b}}$ \\
\hline 1 & 475 & 21800 & 533 & 554 & 2291 & 0.88 & 0.09 \\
\hline 2 & 522 & 42300 & 578 & 646 & 1856 & 0.91 & $<0.01$ \\
\hline 3 & 493 & 28300 & 558 & 613 & 2363 & 0.86 & 0.11 \\
\hline 4 & 494 & 33200 & 562 & 640 & 2449 & 0.90 & 0.45 \\
\hline
\end{tabular}

${ }^{\mathrm{a}}$ In chloroform. ${ }^{\mathrm{b}}$ In the powder state. ${ }^{\mathrm{c}}$ All emission spectra were measured with excitation at $\lambda_{\max }$ in UV/Vis absorption.

For in-depth understanding the relationship between the substituents and the absorption spectra, compounds 1 and 2 were examined by theoretical calculations. ${ }^{6 a}$ After the optimization of the geometrical structures, time-dependent density functional theory (TD-DFT) calculations were performed at the B3LYP level with the 6-31G basis set implemented in the Gaussian 03 program suite. ${ }^{14-15}$ Fig. 5 shows the optimized structures, HOMO and LUMO of $\mathbf{1}$ and 2. The HOMOs of $\mathbf{1}$ and $\mathbf{2}$ are localized on the DPP core and the phenyl ring. Although the contribution of the DPP core to HOMO is greater than the phenyl ring in both compounds, the considerable contribution of the phenyl ring is observed in compound 2 . The extended conjugation of the $\pi$ orbital in compound $\mathbf{2}$ is also confirmed by the small dihedral angle between the DPP core and 
the phenyl ring $\left(22.2^{\circ}\right)$ in the optimized structure (Table 1). The LUMOs of 1 and 2 are similar to each other. The TD-DFT calculation for $\mathbf{1}$ indicates a significant transition from the HOMO to LUMO with large oscillator strength $(f=0.514)$ in the low-lying electronic transitions. The calculated excitation at $477 \mathrm{~nm}$ of $\mathbf{1}$ is in good agreement with the measured $\lambda_{\max }$ of $475 \mathrm{~nm}$. The calculation for 2 indicates a lower-energy excitation $(510 \mathrm{~nm})$ and larger oscillator strength $(f=0.958)$ than those in $\mathbf{1}$. These results correspond to the redshift and large $\varepsilon$ of $\mathbf{2}$ compared with that of $\mathbf{1}$ in the UV/Vis absorption spectra. To clarify the reason for the redshift, the energy levels of the HOMO and LUMO should be considered. While both the HOMO and the LUMO of 2 have higher energy levels than those of $\mathbf{1}$, the difference in the HOMO between $\mathbf{1}$ and $\mathbf{2}$ is more significant $(0.91 \mathrm{eV})$ than that in the LUMO $(0.74 \mathrm{eV})$. Therefore, the electron-donating property of the substituent strongly affects the HOMO of a DPP moiety, resulting in the redshift of the absorbance.

(a)
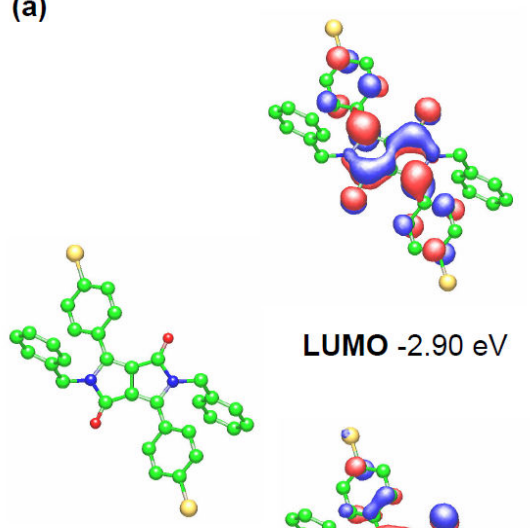

LUMO $-2.90 \mathrm{eV}$

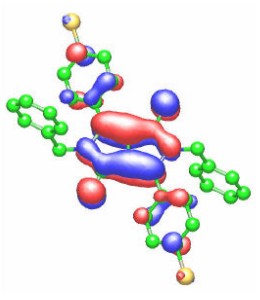

HOMO -5.60 eV (b)
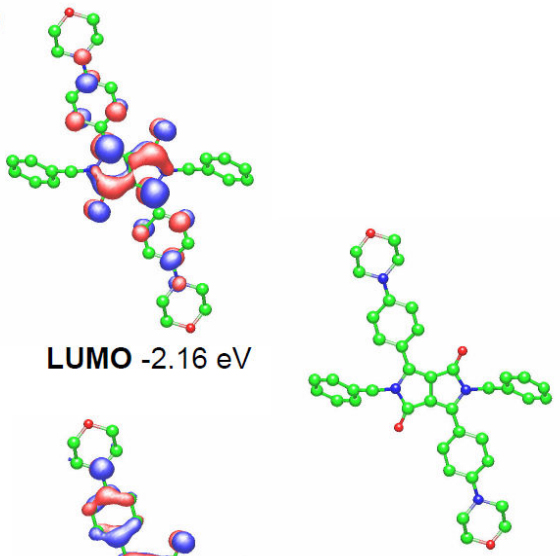

HOMO $-4.69 \mathrm{eV}$

Fig. 5. Optimized structure and contour plots of HOMO and LUMO of (a) 1 and (b) 2.

Compounds 1-4 have high fluorescence quantum yields (0.86-0.91) in the solution state at room temperature (Table 2). The fluorescence quantum yield is almost independent 
of the substituent on the phenyl ring. Fig. 5 shows the emission spectra of compounds 1-4. The wavelength of maximum emission $\left(\lambda_{\mathrm{em}}\right)$ has a similar dependence on the substituent to that of absorption $(\mathbf{2}>\mathbf{4} \approx \mathbf{3}>\mathbf{1})$. Table 2 and Fig. 6 show the emission properties in the powder state. In the solid state, the substituents more strongly affect the emission intensity than they do in solution. The morpholine-substituted compound $\mathbf{2}$ exhibits negligible emission in the solid state $\left(\Phi_{\mathrm{f}}<0.01\right)$. Although compounds $\mathbf{1}$ and $\mathbf{3}$ have significantly lower emission intensity in the solid state than in the solution state, compound 4 maintains its high quantum yield in the solid state $\left(\Phi_{\mathrm{f}}=0.45\right)$. Compared with the solution state, all compounds exhibit a redshift of $\lambda_{\mathrm{em}}$ in the solid state (Fig. 6). Compound 4 exhibits a greatest redshift $(78 \mathrm{~nm})$ than the other DPP derivatives, and its $\lambda_{\mathrm{em}}$ is almost the same as that of compound 2. In the solid state, $\pi$ conjugation of the DPP to the butoxyphenyl group is likely to be larger than that in the solution state owing to the packing force. The extended $\pi$ conjugation provides large Stokes shift in the solid state, which prevent reabsorption of the fluorescence. ${ }^{16}$ That is a possible reason for high quantum yield of $\mathbf{4}$ in the solid state. The solubility of $\mathbf{4}(9.34 \mathrm{mM})$ in $\mathrm{CHCl}_{3}$ is lower than that of $\mathbf{1}(20.7 \mathrm{mM})$ although $\mathbf{4}$ has a flexible butoxy group. The phenomenon is probably due to the tendency of compound 4 to aggregate owing to the extended $\pi$ conjugation of DPP core and biphenyl moiety. 
(a)
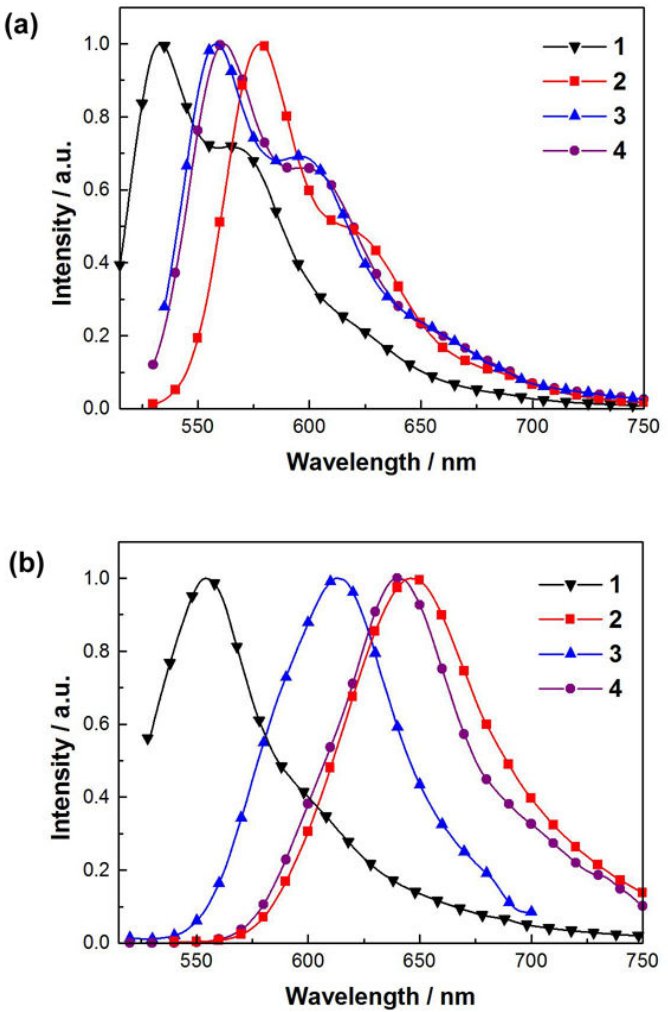

Fig. 6. Emission spectra of 1-4 (a) in $\mathrm{CHCl}_{3}$ and (b) in the solid state.

\section{Conclusion}

Four DPP derivatives with high solubility in nonpolar organic solvents were synthesized from commercially available Pigment red 254 in good yields. The electron-donating property of the substituent increases the amount of the effective conjugation in the molecule, which results in redshifts of UV/Vis absorption and emission in the solution state. In the solid state, the emission of the derivatives depends on the intermolecular interaction such as the $\pi-\pi$ stacking interaction. The compound with the butoxyphenyl substituent $\mathbf{4}$ has a high quantum yield in the solid state. Therefore, the substituent on the phenyl ring affects the chemical properties under an isolated environment in a dilute solution and under a condensed environment in the solid state. 


\section{Exprimental}

General Experimental Procedures: Pigment Red 254, benzyl bromide and morpholine $\begin{array}{llll}\text { were } & \text { from } & \text { Kanto }\end{array}$ 2-(2',6'-dimethoxybiphenyl)-dicyclohexylphosphine (SPhos), 4-butoxyphenyl boronic acid and trans-1-octen-1-ylboronic acid were purchased from SIGMA-ALDRICH. ${ }^{1} \mathrm{H}$ and ${ }^{13} \mathrm{C}\left\{{ }^{1} \mathrm{H}\right\}$ NMR spectra were recorded on a Bruker AVANCE-600 NMR spectrometer and a JEOL EX-270 NMR spectrometer. Elemental analysis was carried out with a Perkin-Elmer $2400 \mathrm{CHN}$ Elemental Analyzer. UV/Vis absorption spectra were recorded on a JASCO V-630iRM spectrophotometer. Emission spectra were recorded on a JASCO FP-6200 spectrophotometer. Fluorescence quantum yields were obtained by a Hamamatsu photonics C9920-02. MALDI-MS spectra were recorded on a Kratos-Shimadzu AXIMA-CFR plus MALDI-TOF MS. High resolution mass spectra were recorded on a JEOL JMS-700 MStation using $m$-nitrobenzyl alcohol as a matrix. SEM image was obtained by a Topcon DS-130. Compound $\mathbf{1}$ and $\mathbf{2}$ were prepared according to the literature methods. ${ }^{8}$

\section{Synthesis of 2,5-Dibenzyl-3,6-bis-(4-oct-1-enyl-phenyl)-2,5-dihydro-pyrrolo[3,4-c]} pyrrole-1,4-dione (3)

A mixture of $\quad \operatorname{Pd}(\mathrm{OAc})_{2} \quad\left(\begin{array}{lllll}8.3 & \mathrm{mg}, & 0.037 & \mathrm{mmol}) \text {, }\end{array}\right.$ 2-(2',6'-dimethoxybiphenyl)-dicyclohexylphosphine (SPhos) (30.4 mg, $0.074 \mathrm{mmol}$ ), trans-1-octen-1-ylboronic acid (290 mg, $1.9 \mathrm{mmol}), 1(400 \mathrm{mg}, 0.74 \mathrm{mmol})$ and $\mathrm{K}_{3} \mathrm{PO}_{4}$ (634.1 mg, $3.0 \mathrm{mmol})$ in THF $(8 \mathrm{~mL})$ was stirred for $22 \mathrm{~h}$ at $60{ }^{\circ} \mathrm{C}$ under a nitrogen atmosphere. After cooling to room temperature, the resulting mixture was extracted with $\mathrm{CHCl}_{3}$ and washed with water. The product was isolated by column chromatography on silica gel using $\mathrm{CHCl}_{3} /$ hexane (4/1) as an eluent (443.2 mg, 95\%). ${ }^{1} \mathrm{H}$ NMR (600 Hz, $\left.\mathrm{CDCl}_{3}\right) \delta 0.89(\mathrm{t}, 6 \mathrm{H}, J=6.9), 1.28-1.36(\mathrm{~m}, 12 \mathrm{H}), 1.46$ (quintet, $\left.4 \mathrm{H}, J=7.1\right), 2.22(\mathrm{dt}$, $4 \mathrm{H}, J=7.1,6.8), 5.00(\mathrm{~s}, 4 \mathrm{H}), 6.33(\mathrm{dt}, 2 \mathrm{H}, J=15.8,6.8), 6.38(\mathrm{~d}, 2 \mathrm{H}, J=15.8)$, 
7.22-7.33 (m, 10H), 7.38 (AA'BB', 4H) 7.73 (AA'BB', 4H); $\left.{ }^{13} \mathrm{C}^{1}{ }^{1} \mathrm{H}\right\}$ NMR $(68 \mathrm{~Hz}$, $\left.\mathrm{CDCl}_{3}\right) \delta 14.2,22.7,29.0,29.2,31.8,33.2,45.8,109.4,125.9,126.1,126.5,127.2$, 128.7, 128.9, 129.3, 134.0, 137.5, 140.9, 148.4, 162.7. MALDI-MS Calcd for $\mathrm{C}_{48} \mathrm{H}_{53} \mathrm{~N}_{2} \mathrm{O}_{2}(\mathrm{M}+\mathrm{H})^{+}$689.4, Found 689.3. Anal. Calcd for $\mathrm{C}_{48} \mathrm{H}_{52} \mathrm{~N}_{2} \mathrm{O}_{2}$ : C, 83.68; H, $7.61 ; \mathrm{N}, 4.07$, Found: C, 83.53; H, 7.62; N, 3.94 .

\section{Synthesis of 2,5-Dibenzyl-3,6-bis-(4'-butoxy-biphenyl-4-yl)-2,5-dihydro-pyrrolo} [3,4-c]pyrrole-1,4-dione (4)

A mixture of $\mathrm{Pd}(\mathrm{OAc})_{2}(2.1 \mathrm{mg}, 0.0093 \mathrm{mmol})$, SPhos (7.6 mg, $\left.0.019 \mathrm{mmol}\right)$, 4-butoxyphenyl boronic acid (109 mg, $0.56 \mathrm{mmol}), 1$ (100 mg, $0.19 \mathrm{mmol}), \mathrm{K}_{3} \mathrm{PO}_{4}(156$ $\mathrm{mg}, 0.74 \mathrm{mmol})$ in THF $(3.7 \mathrm{~mL})$ was stirred for $23 \mathrm{~h}$ at $60{ }^{\circ} \mathrm{C}$ under nitrogen atmosphere. After cooling to room temperature, the resulting mixture was extracted with $\mathrm{CHCl}_{3}$ and washed with water. The product was isolated by column chromatography on silica gel using $\mathrm{CHCl}_{3} /$ toluene (50/1) as an eluent (132.1 mg, 93\%). ${ }^{1} \mathrm{H}$ NMR (600 Hz, $\left.\mathrm{CDCl}_{3}\right) \delta 0.99(\mathrm{t}, 6 \mathrm{H}, J=7.4), 1.48-1.53(\mathrm{~m}, 4 \mathrm{H}), 1.79$ (quintet, $\left.4 \mathrm{H}, J=7.0\right), 4.01(\mathrm{t}, 4 \mathrm{H}$, $J=6.4), 5.06$ (s, 4H), 6.97 (AA'BB', 4H), 7.23-7.34 (m, 10H), 7.54 (AA'BB', 4H), 7.63 (AA'BB', 4H), 7.85 (AA'BB', 4H); ${ }^{13} \mathrm{C}\left\{{ }^{1} \mathrm{H}\right\}$ NMR (68 Hz, $\left.\mathrm{CDCl}_{3}\right) \delta 14.0,19.3,21.6$, $31.4,45.9,67.8,109.5,114.9,125.8,126.5,126.7,127.3,128.1,128.7,129.5,131.9$, 137.5, 143.6, 148.5, 159.3, 162.8. MALDI-MS calcd for $\mathrm{C}_{52} \mathrm{H}_{49} \mathrm{~N}_{2} \mathrm{O}_{4}(\mathrm{M}+\mathrm{H})^{+} 765.4$, Found 765.6. Hi-MS(FAB): 764.3611 (Calcd. for [M]+: 764.3614). Anal. Calcd for $\mathrm{C}_{52} \mathrm{H}_{48} \mathrm{~N}_{2} \mathrm{O}_{4}$ : C, 81.65; H, 6.32; N, 3.66, Found: C, 81.11; H, 6.39; N, 3.72.

\section{Electrochemical measurement}

Electrochemical measurements were performed with a Hokuto Denko HSV-100 automatic polarization system. A conventional three-electrode configuration was used, with glassy carbon working (BAS electrode) and platinum wire auxiliary electrode (Tokuriki, special order) and $0.1 \mathrm{M} \mathrm{AgNO}_{3} / \mathrm{Ag}$ reference (BAS RE-6). Cyclic 
voltammograms were recorded at a scan rate of $100 \mathrm{mVs}^{-1} . \mathrm{Fc}^{+} / \mathrm{Fc}=+115 \mathrm{mV}$ vs. 0.10 $\mathrm{M} \mathrm{AgNO}_{3} / \mathrm{Ag}$, and $+425 \mathrm{mV} v s . \mathrm{SCE}$.

\section{Computational details.}

The geometrical structures were optimized at the B3LYP level for 1-3 with 6-31G basis set implemented in Gaussian 03 programs suits. ${ }^{14,15}$ Using the optimized geometries of 1-3, TD-DFT calculations were performed at the B3LYP level to predict their absorptions.

\section{Crystal structure determination.}

Intensity data were collected on a Rigaku R-AXIS Rapid diffractometer with Mo $K \alpha$ radiation. Crystals were mounted on glass capillary tubes. A full matrix least-squares refinement was used for non-hydrogen atoms with anisotropic thermal parameters method by SHELXL-97 program. Hydrogen atoms were placed at the calculated positions and were included in the structure calculation without further refinement of the parameters. CCDC 765334 and 765335 contains the supplementary crystallographic data for compounds $\mathbf{1}$ and $\mathbf{3}$, respectively. These data can be obtained free of charge via http://www.ccdc.cam.ac.uk/conts/retrieving.html, or from the Cambridge Crystallographic Data Centre, 12 Union Road, Cambridge CB2 1EZ, UK; fax: (+44) 1223-336-033; or e-mail: deposit@ccdc.cam.ac.uk.

\section{Acknowledgement}

The authors thank to Prof. T. Nabeshima, Dr. C. Ikeda and Dr. M. Kyotani for the measurements of quantum yields and SEM image. Dr. H. Fukumoto and Dr. K. Okamoto are acknowledged for the measurements of Mass spectrometry. The authors are grateful to the Chemical Analysis Center of University of Tsukuba for X-ray diffractional studies, elemental analyses and NMR spectroscopy. This work was partly 
supported by Grants-in-Aid for Scientific research form the Ministry of Education, Culture, Sports, Science and Technology, Japan. 


\section{References and notes}

1. (a) Wallquist, O.; Lenz, R. Macromol. Symp. 2002, 187, 617-629; (b) Hao Z.; Iqbal, A. Chem. Soc. Rev. 1997, 26, 203-213; (c) Zambounis, J. S.; Z. Hao,; Iqbal, A. Nature 1997, 388, 131-132; (d) Wallquist, O. In High Performance Pigments; Smith, H. M., Ed.; Wiley-VCH: Weinheim, 2002; pp 159-184.

2. (a) Zhang, K.; Tieke, B. Macromolecules 2008, 41, 7287-7295; (b) Fischer, G. M.; Ehlers, A. P.; Zumbusch, A.; Daltrozzo, E. Angew. Chem. Int. Ed. 2007, 46, 3750-3753; (c) Cao, D.; Liu, Q.; Zeng, W.; Han, S.; Peng, J.; Liu, S. Macromolecules 2006, 39, 8347-8355.

3. Fukuda, M.; Kodama, K.; Yamamoto, H.; Mito, K. Dyes Pigments 2004, 63, $115-125$.

4. (a) Qu, S.; Wu, W.; Hua, J.; Kong, C.; Long, Y.; Tian, H. J. Phys, Chem, C 2010, 114, 1343-1349; (b) Zhou, E.; Wei, Q.; Yamakawa, S.; Zhang, Y.; Tajima, K.; Yang, C.; Hashimoto, K. Macromolecules 2010, 43, 821-826; (c) Bijleveld, J. C.; Zoombelt, A. P.; Mathijssen, S. G. J.; Wienk, M. M.; Turbiez, M.; de Leeuw, D. M.; Janssen, R. A. J. J. Am. Chem. Soc. 2009, 131, 16616-16617; (d) Huo, L.; Hou, J.; Chen, H.; Zhang, S.; Jiang, Y.; Chen, T. L.; Yang, Y. Macromolecules 2009, 42, 6564-6571; (e) Zou, Y.; Gendron, D.; Badrou-Aïch, R.; Najari, A.; Tao, Y.; Leclerc, M. Macromolecules 2009, 42, 2891-2894; (f) Yu, C.; Chen, C.; Chan, S.; Hwang, G.; Ting, C. Chem. Mater. 2009, 21, 3262-3269. (g)Tamayo, A. B.; Walker, B.; Nguyen, T. J. Phys, Chem, C 2008, 112, 11545-11551; (h) Wienk, M. M.; Turbiez, M.; Gilot, J.; Janssen, R. A. J. Adv. Mater. 2008, 20, 2556-2560.

5. (a) Bürgi, L.; Turbiez, M.; Pfeiffer, R.; Bienewald, F.; Kirner, H.; Winnewisser, C. Adv. Mater. 2008, 20, 2217-2224; (b) Tantiwiwat, M.; Tamayo, A.; Luu, N.; Dang, X.; Nguyen, T. J. Phys, Chem, C 2008, 112, 17402-17407.

6. Recent examples of a postfunctionalization of DPP. (a) Luňák Jr., S.; Vyňuchal, J.; Vala, M.; Havel, L.; Hrdina, R. Dyes Pigments 2009, 82, 102-108; (b) Guo, E. Q.; Ren, P. H.; Zhang, Y. L.; Zhang, H. C.; Yang, W. J. Chem. Commun. 2009, 5859-5861.

7. Recent examples of fluorophore syntheses by organometallic catalysts. (a) Bhosale, S. V.; Kalyankar, M. B.; Bhosake, S. V.; Langford, S. J.; Reid, E. F.; Hogan, C. F. New. J. Chem. 2009, 33, 2409-2413; (b) Shimizu, M.; Tatsumi, H.; Mochida, K.; 
Shimono, K.; Hiyama, T. Chem. Asian J. 2009, 4, 1289; (c) Son, H.; Han, W.; Yoo, D.; Min, K.; Kwon, S.; Ko, J.; Kang, S. O. J. Org. Chem. 2009, 74, 3175-3178. (d) Ulrich, G.; Ziessel, R.; Harriman, A. Angew. Chem. Int. Ed. 2008, 47, 1184-1201.

8. Yamagata, T.; Kuwabara, J.; Kanbara, T. Tetrahedron Lett. 2010, 51, 1596-1599.

9. (a) Littke, A. F.; Fu, G. C. Angew. Chem. Int. Ed. 2002, 41, 4176-4211. (b) Bedford, R. B.; Cazin, C. S. J.; Holder, D. Coord. Chem. Rev. 2004, 248, 2283-2321.

10. Langhals, H.; Potrawa, T.; Nöth, H.; Linti, G. A. Angew. Chem. Int. Ed. Engl. 1989, $28,478-480$.

11. Biscoe, M. R.; Barder, T. E.; Buchwald, S. L. Angew. Chem. Int. Ed. 2007, 46, $7232-7235$

12. Crystallographic details for $1: \mathrm{C}_{32} \mathrm{H}_{22} \mathrm{Cl}_{2} \mathrm{~N}_{2} \mathrm{O}_{2}, M=537.44, T=81(2) \mathrm{K}$, Monoclinic space group $\mathrm{P} 21 / \mathrm{c}, a=8.4020(5) \AA, b=10.0382(7) \AA, c=14.7375(8) \AA, \beta=$ 92.8930(17) $, V=1241.38(13) \AA^{3}, Z=2,11649$ measured reflections, 2782 independent reflections $\left[R_{\text {int }}=0.049\right], R_{1}(I>2 \sigma(I))=0.0425, w R_{2}$ (all reflections) $=$ $0.1038, \mathrm{GOF}=1.052 . \mathrm{CCDC} 765334$.

13. Crystallographic details for 3: $\mathrm{C}_{48} \mathrm{H}_{52} \mathrm{~N}_{2} \mathrm{O}_{2}, M=688.95, T=81(2) \mathrm{K}$, Monoclinic space group P21/c, $a=10.2584(10) \AA, b=14.8429(11) \AA, c=25.116(2) \AA, \beta=$ 93.096(3) $)^{\mathrm{o}}, V=3818.6(6) \AA^{3}, Z=4,36180$ measured reflections, 8706 independent reflections $\left[R_{\text {int }}=0.149\right], R_{1}(I>2 \sigma(I))=0.0859, w R_{2}($ all reflections $)=0.2679, \mathrm{GOF}=$ 1.078. CCDC 765335.

14. (a) Frisch, M. J.; Trucks, G. W.; Schlegel, H. B.; Scuseria, G. E.; Robb, M. A.; Cheeseman, J. R.; Montgomery, Jr., J. A.; Vreven, T.; Kudin, K. N.; Burant, J. C.; Millam, J. M.; Iyengar, S. S.; Tomasi, J.; Barone, V.; Mennucci, B.; Cossi, M.; Scalmani, G.; Rega, N.; Petersson, G. A.; Nakatsuji, H.; Hada, M.; Ehara, M.; Toyota, K.; Fukuda, R.; Hasegawa, J.; Ishida, M.; Nakajima, T.; Honda, Y.; Kitao, O.; Nakai, H.; Klene, M.; Li, X.; Knox, J. E.; Hratchian, H. P.; Cross, J. B.; Bakken, V.; Adamo, C.; Jaramillo, J.; Gomperts, R.; Stratmann, R. E.; Yazyev, O.; Austin, A. J.; Cammi, R.; Pomelli, C.; Ochterski, J. W.; Ayala, P. Y.; Morokuma, K.; Voth, G. A.; Salvador, P.; Dannenberg, J. J.; Zakrzewski, V. G.; Dapprich, S.; Daniels, A. D.; Strain, M. C.; Farkas, O.; Malick, D. K.; Rabuck, A. D.; Raghavachari, K.; Foresman, J. B.; Ortiz, 
J. V.; Cui, Q.; Baboul, A. G.; Clifford, S.; Cioslowski, J.; Stefanov, B. B.; Liu, G.; Liashenko, A.; Piskorz, P.; Komaromi, I.; Martin, R. L.; Fox, D. J.; Keith, T.; Al-Laham, M. A.; Peng, C. Y.; Nanayakkara, A.; Challacombe, M.; Gill, P. M. W.; Johnson, B.; Chen, W.; Wong, M. W.; Gonzalez, C.; Pople, J. A. Gaussian 03, Revision D.01, Gaussian, Inc., Wallingford CT, 2004; (b) Foster, J. P.; Weinhold, F. J. Am. Chem. Soc., 1980, 102, 7211-7218; (c) Glendening, E. D.; Reed, A. E.; Carpenter, J. E.; Weinhold, F. Version 3.1.

15. GaussView, Version 4.1, Roy Dennington II, Todd Keith, John Millam, Semichem, Inc., Shawnee Mission, KS, 2007.

16. Katoh, R.; Suzuki, K.; Furube, A.; Kotani, M.; Tokumaru, K. J. Phys, Chem. C 2009, $113,2961-2965$. 